\title{
Identity as a Determinant of the Overreporting of Church Attendance in Canada
}

\author{
PHILIP S. BRENNER \\ Survey Research Center \\ University of Michigan
}

\begin{abstract}
Recent work has demonstrated that Canadians overreport church attendance at rates similar to respondents in the United States. Overreporting in the United States has been attributed to the importance of religious identity; causes of Canadian overreporting have not been examined. This article draws upon Stryker's identity theory to explain why Canadian survey respondents overreport church attendance. The 2005 Canadian General Social Survey contains observed measures of attendance from both a conventional survey question and a time diary, allowing a direct and rigorous test of the identity explanation. Findings suggest that rates of Canadian overreporting, at about 50 percent, rival rates of overreporting in the United States. Moreover, like overreporting in the United States, Canadian overreporting may be affected by an identity process during the survey interview. Finally, implications for measuring religiosity in both countries are discussed.
\end{abstract}

Keywords: Canada, church attendance, identity, overreporting.

\section{INTRODUCTION}

Research comparing a number of advanced Western democracies has established that only survey respondents in the United States and Canada substantively overreport the frequency of their church attendance (Brenner 2011a). Studies suggest that approximately half of the North Americans who report attending religious services overreport. Hadaway, Marler, and Chaves (1993) found an overreport of about 83 percent amongst Ashtabula County (Ohio) Protestants when comparing a survey estimate to an estimate based on observation and counting. Similar results emerged in Oxford County, Ontario (Hadaway and Marler 1997), from a sample of Presbyterians (Marcum 1999), among Catholics (Chaves and Cavendish 1994), in an evangelical congregation (Marler and Hadaway 1999), and in a comparison between time diaries and conventional survey estimates (Brenner 2011a; Presser and Stinson 1998).

Recent work has investigated the cause of the error in the conventional survey self-report using a hypothesis based on Stryker's identity theory (1980/2003). Expanding on the work of Presser and Stinson (1998), Brenner (2011b) compared estimates of attendance from the American Time Use Study (ATUS) and the American General Social Survey (AGSS) to predict overreporting using a measure of religious identity importance. Identity importance is the subjective value an individual places on an identity (Ervin and Stryker 2001; Stryker 1980/2003). High levels of identity importance can bias the measurement of identity salience (i.e., propensity of identity enactment) especially when using conventional survey questions (see Burke 1980; Stryker and Burke 2000; Stryker and Serpe 1994). The time diary is used as a comparator because it lacks this source of bias (Presser and Stinson 1998). Findings suggested that overreporting in the United

Acknowledgements: This work was supported by a Doctoral Dissertation Improvement Grant from the National Science Foundation [(SES-0824759)]. The author would like to thank John DeLamater, Fred Conrad, Chan Zhang, Kimberly Turner, three anonymous reviewers, and Marie Cornwall for comments on earlier versions of this article.

Correspondence should be addressed to Philip S. Brenner, Department of Sociology, University of Massachusetts Boston, 100 Morrissey Blvd., Boston, MA, 02125.E-mail: philip.brenner@umb.edu 
States might at least partially be caused by an identity process in the survey interview (Brenner 2011b). The importance placed on one's religious identity generates both relatively high rates of attendance and high rates of overreporting in the U.S. sample. That is, identity prompts Americans to either attend or to say that they attended even when they did not (Hadaway, Marler, and Chaves 1998).

Canadian overreporting, however, has not been similarly investigated. The Canadian case is a clear next step in this research program for two reasons; one theoretical and one methodological. First, as an advanced Western democracy where substantial overreporting of church attendance has been found, Canada presents an important additional test of the identity approach. If identity importance explains overreporting in the United States, but not among Canadians, the hypothesis would be quite limited in its scope. However, if identity explains overreporting in both countries, it would lend further credence to identity importance as a general explanation for overreporting of church attendance and, possibly, other normative behaviors.

Second, Canadian data allow for an analysis not possible with other datasets. The largest problem with comparing attendance measures from conventional and time diary surveys is that studies with both types of attendance reports are extremely rare, offering very small analytical sample sizes where they exist at all. Comparisons between these two measures of attendance have, until now, been undertaken either on the margins or using methods with strong limitations. Brenner's (2011b) comparisons of the ATUS and AGSS relied on a multiple imputation procedure to bring together two different datasets from two different samples from the same target population. This less than ideal analysis generated complete cases with both conventional and diary measures of attendance. Although sensitivity analyses suggested that the imputation procedure worked quite well, a preferable situation would be one in which all necessary variables are observed for every respondent.

Unlike existing data in the United States, Cycle 19 of the Canadian General Social Survey (CGSS-19) measured attendance using both a conventional survey question and a time diary, allowing a more direct and rigorous test of the identity hypothesis. The size and richness of this dataset allows computation of an overreported-attendance indicator using both conventional and diary measures of attendance without the need for multiple imputation of either measure of attendance.

\section{Data ANd Methods}

CGSS-19 was fielded by Statistics Canada from January 2005 to December 2005 (Statistics Canada 2008). The target population for the CGSS-19 included all persons 15 years of age or older in Canada, excluding the Yukon, Northwest Territories, Nunavut, and institutionalized persons. The random digit dialed (RDD) sample was stratified by geographic area. Contact was attempted with 33,470 households, yielding 19,597 completed interviews and a response rate (AAPOR 1) of 58.6 percent. Interviews were conducted using computer-assisted telephone interviewing (CATI) in the respondent's preferred language, English or French.

Interviews were structured in 14 sections. Key variables used here were conveniently spaced widely apart and in a fortuitous order. The time diary section was conducted very early in the interview (Section 2); the conventional religion questions were the penultimate questions in the interview (Section 14). This spacing was sufficient for keeping measurement independent, preventing the respondent from producing artificial concordance between answers, but close enough to prevent the possibility of actual change between the two measurements (Alwin 2007).

The dependent variable, overreporting, is computed as the positive difference between the diary and conventional survey measures of attendance (see Table 1). The time diary provides a relatively unbiased measure of attendance (see Brenner 2011b, 2011c; Presser and Stinson 1998). This dichotomous measure indicates whether the respondent reported attending on the diary day. 


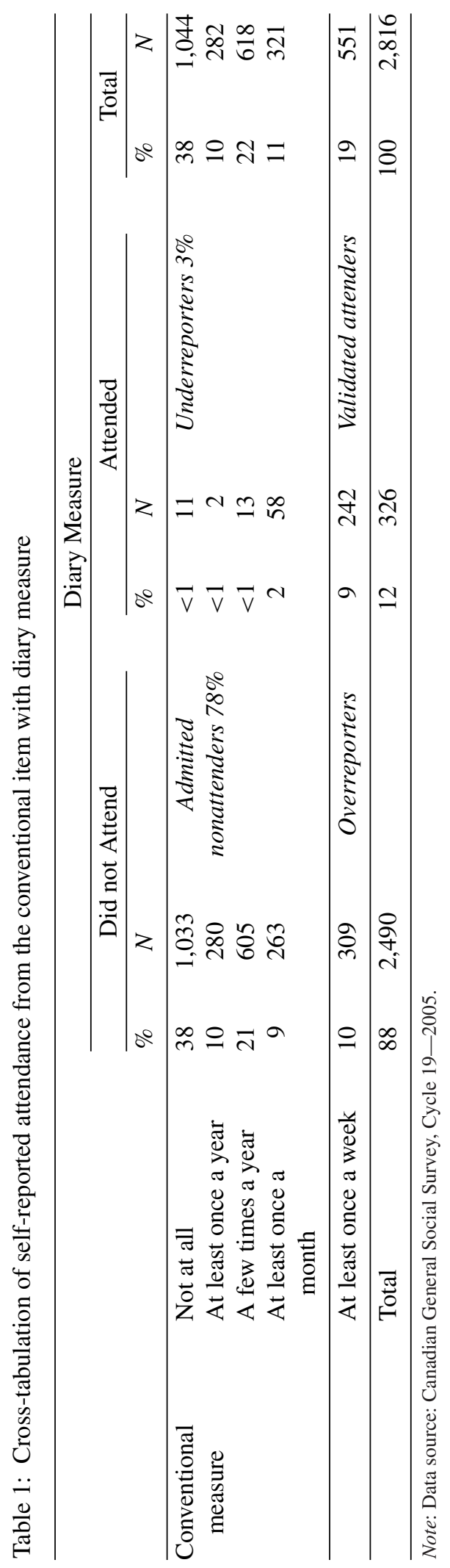


Analysis was limited to those respondents randomly selected to report on their Sunday activity. To minimize memory errors, most Sunday diaries were completed during interviews within 24 hours and all were completed within 48 hours (Allan, Dryburgh, and Holor 2006).

The conventional survey measure asked respondents how often they attend religious services: "Other than on special occasions (such as weddings, funerals or baptisms), how often did you attend religious services or meetings in the last 12 months? Was it at least once a week, at least once a month, a few times a year, at least once a year, or not at all?"1 This measure is dichotomized for the calculation of overreporting, as those who attend at least once a week (1) and all others (0), yielding a conservative estimate of overreporting, comparable to prior research (Brenner 2011a). Although respondents reporting monthly or less frequent attendance may actually be overreporting, for the purposes of this analysis they are categorized as accurate reporters. Given even this conservative operationalization, the rate of overreporting is striking. Of those respondents reporting at least weekly attendance, over half $(309 / 551=54$ percent $)$ do not report attending on the diary. These operationalizations result in the distribution shown in Table $1 .^{2}$

Respondents with religious affiliations for which Sunday is not the traditional day of worship (e.g., Jews, Muslims) are excluded from these analyses. Christian groups whose worship day is not Sunday (e.g., Adventists) could not be excluded as CGSS denominational categories do not allow for such fine-grained distinctions. However, these groups comprise a very small segment of Canadians, estimated to be about .2 percent, ${ }^{3}$ resulting in a negligible amount of error. Others who attend services exclusively on non-Sundays are also included in these analyses and could potentially inflate the estimate of overreporting. Smith (1998) estimates the rate of exclusive non-Sunday attendance in the United States at about 8 percent of regular attenders. Applying this estimate to Canada would increase the CGSS diary attendance rate by only 1 percentage point, yielding a very small moderation in the rate of overreporting.

Some number of respondents who attend nearly every week (about three times a month) may report attending every week. Rather than reporting objective behavior, the respondent interprets the survey question pragmatically (Clark and Schober 1992; Schwarz 1996; Sudman, Bradburn, and Schwarz 1996) influenced by a desire to self-present in an identity-consistent light (Hadaway, Marler, and Chaves 1998) leading to an identity affirming answer, even if it overestimates actual behavior. Even though this fits into the category of overreporting, some flexibility in operationalization may be enlightening. Even if a quarter of those reporting at least weekly attendance were moved from the overreporting category to the accurate reporting category, 42 percent of the self-reported attenders would still be classified as overreporters. ${ }^{4}$ Although it would be preferable to have both measures of attendance from an identical reference period (e.g., a single Sunday), this situation still provides a decent approximation of that ideal. Rates of attendance from measures of yearly behavior have compared well with those with weekly reference periods in existing research (Brenner 2011b). Data from years of the AGSS in which attendance is measured with both yearly and weekly reference periods suggests that these measures correlate strongly as measured (point-biserial $r=.77)$ and dichotomized $(\phi=.78)$.

\footnotetext{
${ }^{1}$ A small number of respondents (181, or 6 percent of the sample) who reported "none" on the religious affiliation question and reported that religion is "not at all important" were not asked this question. Rather than delete these cases as missing, these respondents have been recoded as nonattenders.

${ }^{2}$ The conservative operationalization of overreporting leads to a likely overestimation of underreporting. Even given this problem, virtually no respondents underreport. Therefore, this category will not be discussed further in this article.

${ }^{3}$ Estimate from Statistics Canada, 2001 Census of Population.

${ }^{4}$ A similar phenomenon is likely happening with respondents in the lower frequency categories. As all respondents in these categories have been operationalized to be accurate reporters, they contribute not to an overestimation of overreporting, but to its underestimation. There is likely some amount of canceling out happening between miscategorized overreporters from the higher frequency categories and miscategorized accurate reporters from the lower frequency categories.
} 


\section{Independent Variables}

Religious identity importance is measured with the following question: "How important are your religious or spiritual beliefs to the way you live your life? Would you say they are very important, somewhat important, not very important, or not at all important?" Importance is included as a set of three dummy variables (not at all or not very, somewhat, and very important). Thirty percent of respondents report that their religious beliefs are not at all or not very important.

Religious affiliation is also included as existing work suggests differential overreporting by denominational category. For example, Presser and Stinson (1998) found that American Catholics were more likely to overreport compared to Protestants. Religious affiliation is included here in the following categories: Catholic, Protestant, other Christian, and none. Because religious affiliation is associated with linguistic group and provincial citizenship in Canada, both region and the primary language spoken will be included. Language is included in three categories: French, English, and other. Region is included in five categories: (1) the Atlantic/Maritime provinces (Newfoundland and Labrador, New Brunswick, Nova Scotia, and Prince Edward Island), (2) Quebec, (3) Ontario, (4) the Prairie region (Alberta, Manitoba, and Saskatchewan), and (5) British Columbia.

\section{Demographic Controls}

A number of demographic variables often associated with church attendance in the extant literature (e.g., women, older adults, married adults, and those with young children) are also included. Gender and presence of children in the household are included as dichotomous variables. Marital status is included as a set of dummy variables: married, divorced or separated, widowed, and never married. Age is also included as a set of dummy variables in the following ranges: $18-24,25-34,35-44,45-54,55-64$, and 65 years of age and older. Education is included in three categories: completed primary and less, secondary completion including vocational or some postsecondary, and college degree or higher. Income is divided into quartiles: lowest quartile, middle half, and highest quartile.

\section{Models}

A series of logistic regression models (Stata: logit) are estimated to explain variation in overreporting. All models use person-level weights provided by Statistics Canada. The first model predicts overreporting with religious identity importance and demographic covariates. As religious affiliation, language, and region may be highly correlated, they are entered into the model separately to test for collinearity. Interactions between key independent variables are also tested. Models are then estimated to compare overreporters with (1) other self-reported attenders (verified attenders) and with (2) other nonattenders (admitted nonattenders). Each of these models tests a hypothesis based in identity theory. First, if identity is at the root of both actual attendance and overreporting, these two groups should not differ in the value they place on their religious identity. Second, if identity is at the root of claims of attendance, admitted nonattenders and overreporters should differ dramatically in the value they place on their religious identity.

\section{RESULTS}

Model 1 predicts overreporting using religious identity importance and demographic covariates. Importance is a powerful predictor in this baseline model. Respondents claiming that religion is somewhat or very important have 8 and 63 times the odds of overreporting $(\beta=2.1$ 
and $4.1 ; p \leq .001)$, respectively, compared to respondents who claimed religion is not very or not at all important.

Model 2 adds religious affiliation, primary language spoken in the household, and region of residence to the analysis. Religious affiliation is a strong predictor of overreporting. Compared to Protestants, Catholics are twice as likely to overreport $(\beta=.73 ; p \leq .001)$ and the unaffiliated have only about a quarter the odds $(\beta=-1.32 ; p \leq .01)$ of overreporting. Neither language nor region reaches conventional levels of statistical significance in this model. Even with these additional controls, importance remains a very powerful predictor of overreporting, with respondents claiming that religion is somewhat $(\beta=1.7 ; p \leq .01)$ or very important $(\beta=3.9 ; p \leq .001)$ having 5.5 and 47 times the odds of overreporting compared to respondents claiming low or no religious identity importance.

Model 2 was reestimated to test if collinearity was preventing a significant finding for language and region in the full Model 2. However, even when entered individually, neither language nor region rises to statistical significance (results not shown). Two interactions were also tested although neither the interaction between affiliation and language nor the interaction between identity importance and religious affiliation rose to conventional levels of statistical significance. As none of these models yield significant effects or an improved model, they are not included in Table 2.

Model 3 reestimates Model 2 for only self-reported attenders - that is, those respondents who claimed weekly attendance on the conventional survey measure. As hypothesized, importance fails to distinguish between actual attenders and overreporters. Religious affiliation is again a strong predictor of overreporting. Catholics who report attendance on the conventional measure have nearly four times the odds of Protestants of being overreporters $(\beta=1.36 ; p \leq .001)$. Small cell size prevents the unaffiliated from being included in this model as only six unaffiliated respondents reported attending on the conventional measure. As in the prior model, Francophone Canadians are no more likely to overreport when analysis is limited to self-reported attenders. The "other" categories for these variables (other Christian and other language) both rise to statistical significance, but their small cell sizes and their inherent heterogeneity caution against strong inferences. Finally, in no region do self-reported attenders differ from those in Ontario in their likelihood to overreport.

Model 4 reestimates Model 2 for only nonattenders-that is, those respondents who did not report attending on the diary. As hypothesized, importance again rises to statistical significance, distinguishing between admitted nonattenders and overreporters. Respondents claiming that religion is either somewhat $(\beta=1.7 ; p \leq .001)$ or very $(\beta=4.2 ; p \leq .001)$ important have 5.5 and 67 times the odds of overreporting, compared to respondents reporting low or no importance. Language and region do not predict overreporting amongst nonattenders, although religious affiliation does. Compared to nonattending Protestants, nonattending Catholics have a 57 percent increase in the odds of overreporting $(\beta=.45 ; p \leq .05)$ and the unaffiliated have an 85 percent reduction in the odds of overreporting $(\beta=-1.9 ; p \leq .001)$.

\section{Discussion}

Canadians overreport their church attendance at a rate comparable to Americans (Brenner 2011a; Hadaway and Marler 1997). In the 2005 Canadian General Social Survey, 19 percent of respondents claimed at least weekly attendance, but fewer than half of these respondents actually attended on randomly selected Sundays. What could account for this high level of misreporting? Research on overreporting in the United States suggests that the importance of a religious identity prompts a report of attendance at a level higher than actual behavior would warrant (Brenner 2011b, 2011c; Hadaway, Marler, and Chaves 1998; Presser and Stinson 1998). As explained by Hadaway, Marler, and Chaves, "overreporting is generated by the combination 
Table 2: Logistic regression models predicting overreported attendance; reference category in parentheses

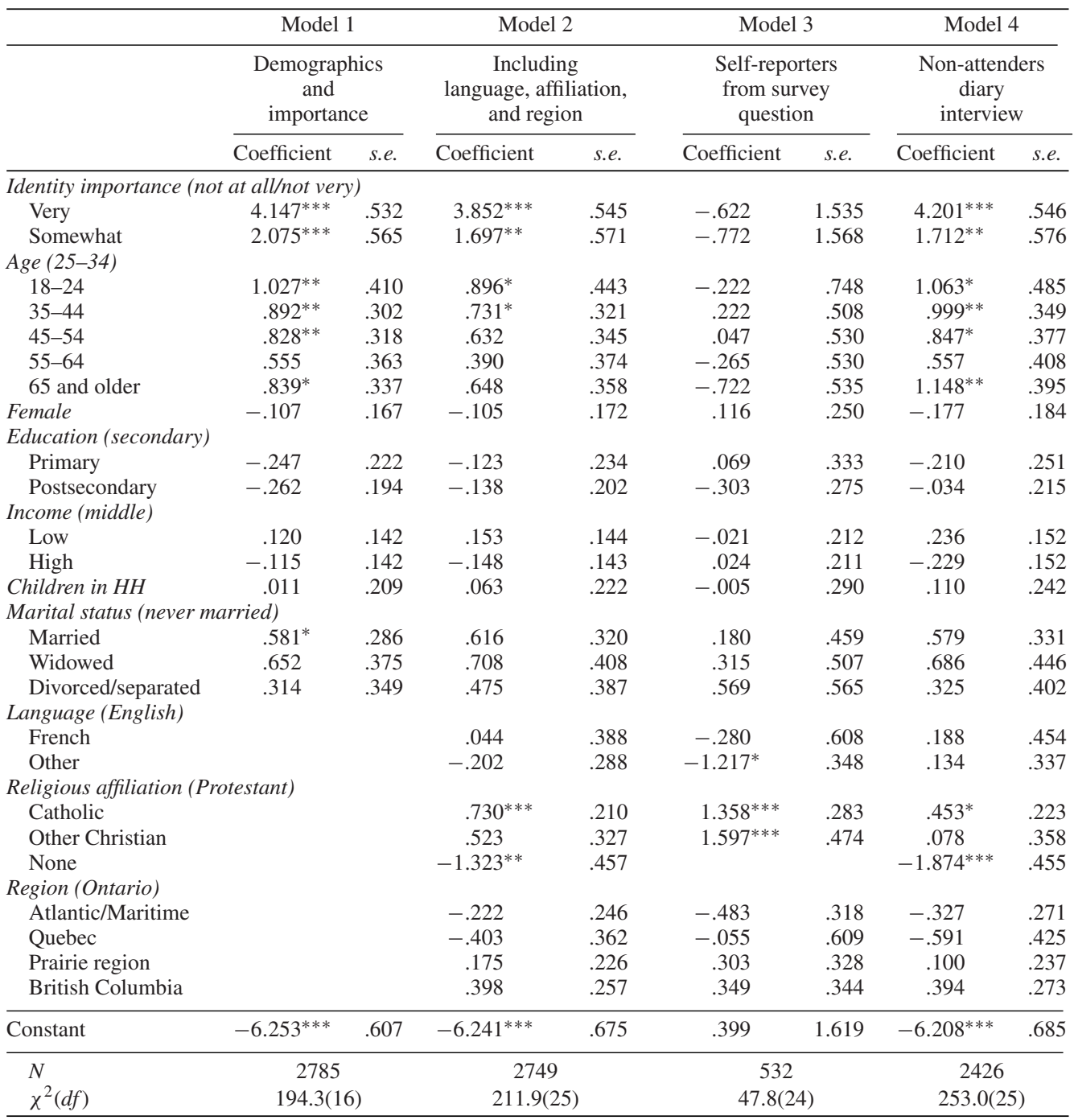

Notes: Data source: Canadian General Social Survey, Cycle 19-2005.

$* * * p \leq 0.001, * * p \leq 0.01, * p \leq 0.05$.

of a respondent's desire to report truthfully his or her identity as a religious, church-going person and the perception that the attendance question is really about this identity rather than about actual attendance" (1998:127, emphasis in original). Is the same identity process occurring in Canada?

To answer this question, overreporting in the CGSS-19 was predicted using a measure of religious identity importance. The unique quality of these data-containing both conventional and diary measures of attendance-provided an excellent opportunity to more rigorously test the hypotheses based on identity theory. Mirroring the American case (Brenner 2011b, 2011c), Canadian overreporting is strongly associated with religious identity importance. The greater the importance of a respondent's religious identity, the greater the odds that s/he will overreport. This association is maintained even when religious affiliation, primary language spoken in the home, province or region, and a set of demographic variables commonly associated with frequent church attendance are included as controls. 
This relationship was further elucidated in two subgroup analyses. Looking first at selfreported attenders, the hypothesis based on identity theory suggests that importance should fail to distinguish between actual attenders and overreporters. Identity theory conceptualizes salience as the propensity to perform an identity and importance as the subjective value the individual places on an identity. During conventional survey measurement of attendance, the measure of salience may be biased by a highly important religious identity, thereby artificially creating concordance. Alternatively, if overreporting was generated by a process unrelated to identity (e.g., random misremembering or forgetting), a difference should be expected to emerge between actual attenders and overreporters. In line with the hypotheses of identity theory, overreporters claim a level of religious identity importance on par with actual attenders.

The second subgroup analysis tested the identity hypothesis that importance should be a strong predictor distinguishing between admitted nonattenders and overreporters. Alternatively, if overreporting was generated by a process unrelated to identity, no difference in importance should be observed between admitted nonattenders and overreporters. In line with the identity hypothesis, overreporters look very different from other nonattenders, rating the importance of their religious identities much higher than the admitted nonattenders.

To be clear, the identity explanation does not necessitate an intentional misreport. Quite the opposite, as highlighted in the quotation from Hadaway, Marler, and Chaves (1998), the respondent's motivation is aimed at truthfully presenting his or her identity as a churchgoing person, not in fraudulently exaggerating his or her behavior. The overreport is part of a cognitive process in which the respondent interprets the survey question pragmatically rather than semantically. This interpretation allows the respondent to bring his or her response into alignment with his or her identity as a religious person. Whether it is caused by identity, some other process, or jointly caused by multiple processes, these results clearly demonstrate that overreporting is at least associated with identity importance. Notably, none of the demographic covariates commonly associated with religious behaviors and religiosity included here moderate the relationship between identity importance and overreporting. However, exploring processes that could potentially moderate the identity-overreporting relationship is an avenue for future research.

\section{Conclusion}

The survey interview is certainly not a typical, everyday type of interaction, but it is a very important one. The products of survey research not only reflect the self-concepts of those in society, but also help to shape those self-concepts (Igo 2008). However, as is true of nearly all interpersonal interaction, inaccurate information in the survey interview can change understandings and lead to unwarranted inferences. These measurement errors are reflected in statistics that can yield errant understandings of the society they are supposed to accurately describe.

Survey research has described Canada as a middle ground of sorts with rates of attendance in between Europe and the United States (Berger, Davie, and Fokas 2008; Martin 2000). However, similar to those in the United States, conventional survey estimates in Canada fail to tell the whole story. Like their neighbors to the south, Canadians tend to overreport their church attendance, creating an interesting set of comparisons linking Canada with Europe in its rate of actual attendance and with the United States in its rate of overreporting. Moreover, like that in the United States, Canadian overreporting is strongly associated with religious identity importance.

As this suggests, the overreporting of church attendance is more than just a measurement error to be corrected. It is an opportunity to better understand religiosity and religious behavior both within societies and from a comparative perspective (Schuman 1982). Following Brenner (2011b), these findings demonstrate the robustness of and lend strong support to the identity-based explanation of overreporting of church attendance. They also further critique the understanding of the United States as exceptional in its religious behavior. American religious attendance is not 
exceptional in its rate of attendance (Brenner 2011a), in its rate of overreporting, nor, arguably, in its apparent cause of overreporting.

\section{REFERENCES}

Allan, Catherine, Heather Dryburgh, and Dave Holor. 2006. Canada's general social survey on time use: Challenges and potential. General Social Survey on Time Use, Catalogue No. 89-622-XIE. Ottawa, Canada: Statistics Canada.

Alwin, Duane F. 2007. Margins of error: A study of reliability in survey measurement. Hoboken, NJ: Wiley.

Berger, Peter, Grace Davie, and Effie Fokas. 2008. Religious America, secular Europe? A theme and variations. Burlington, VT: Ashgate.

Brenner, Philip S. 2011a. Exceptional behavior or exceptional identity? Overreporting of church attendance in the US. Public Opinion Quarterly 75(1):19-41.

- 2011b. Identity importance and the overreporting of religious service attendance: Multiple imputation of religious service attendance using the American Time Use Study and the General Social Survey. Journal for the Scientific Study of Religion 50(1):103-15.

- 2011c. Investigating the biasing effect of identity in self-reports of socially desirable behavior. Sociological Focus 44(1):55-75.

Burke, Peter J. 1980. The self: Measurement implications from a symbolic interactionist perspective. Social Psychology Quarterly 43(1):18-29.

Chaves, Mark and James C. Cavendish. 1994. More evidence on US Catholic church attendance. Journal for the Scientific Study of Religion 33(4):376-81.

Clark, Herbert H. and Michael F. Schober. 1992. Asking questions and influencing answers. In Questions about questions: Inquiries into the cognitive bases of surveys, edited by Judith M. Tanur, pp. 15-48. New York: Russell Sage.

Ervin, Laurie H. and Sheldon Stryker. 2001. Theorizing the relationship between self-esteem and identity. In Extending self-esteem theory and research: Sociological and psychological currents, edited by Timothy Joseph Owens, Sheldon Stryker, and Norman Goodman, pp. 29-55. New York: Cambridge University Press.

Hadaway, C. Kirk and Penny Long Marler. 1997. Do Canadians overreport church membership and attendance?: A case study of religion in a Canadian county. Paper presented at the 1997 meeting of the Association for the Sociology of Religion, Toronto, Canada, August 10.

Hadaway, C. Kirk, Penny Long Marler, and Mark Chaves. 1993. What the polls don't show: A closer look as US church attendance. American Sociological Review 58(6):741-52.

-1998. Overreporting church attendance in America: Evidence that demands the same verdict. American Sociological Review 63(1):122-30.

Igo, Sarah E. 2008. The averaged American: Surveys, citizens, and the making of a mass public. Cambridge, MA: Harvard University Press.

Marcum, John P. 1999. Measuring church attendance: A further look. Review of Religious Research 41(1):121-30.

Marler, Penny Long and C. Kirk Hadaway. 1999. Testing the attendance gap in a conservative church. Sociology of Religion 60(2):175-86.

Martin, David. 2000. Canada in comparative perspective. In Rethinking church, state, and modernity: Canada between Europe and America, edited by David Lyon and Marguerite Van Die, pp. 23-33. Toronto, Canada: University of Toronto Press.

Presser, Stanley and Linda Stinson. 1998. Data collection mode and social desirability bias in self-reported religious attendance. American Sociological Review 63(1):137-45.

Schuman, Howard. 1982. Artifacts are in the eye of the beholder. American Sociologist 17(1):21-28.

Schwarz, Norbert. 1996. Cognition and communication: Judgmental biases, research methods, and the logic of conversation. Mahwah, N: Lawrence Erlbaum.

Smith, Tom W. 1998. A review of church attendance measures. American Sociological Review 63(1):131-36.

Statistics Canada. 2008. General Social Survey, cycle 19: Time use, public use microdata file, 2005 [computer file]. Ottawa, Canada: Statistics Canada [producer].

Stryker, Sheldon. 1980/2003. Symbolic interactionism: A social structural version. Caldwell, NJ: Blackburn Press.

Stryker, Sheldon and Peter J. Burke. 2000. The past, present, and future of an identity theory. Social Psychology Quarterly 63(4):284-97.

Stryker, Sheldon and Richard T. Serpe. 1994. Identity salience and psychological centrality: Equivalent, overlapping, or complimentary concepts?" Social Psychology Quarterly, 57(1):16-35.

Sudman, Seymour, Norman M. Bradburn, and Norbert Schwarz. 1996. Thinking about answers: The application of cognitive processes to survey methodology. San Francisco: Jossey-Bass. 